\title{
When are Endografts the Best Treatment for Aortic Infection? And When are they Not?
}

\author{
Francesco Setacci ${ }^{1,2}$ and Massimo Fioranelli ${ }^{3,4^{*}}$ \\ ${ }^{1}$ Department of Surgery, Sapienza University of Rome, Rome, Italy \\ ${ }^{2}$ Department of Medicine, Surgery and Neuroscience, University of Siena, Italy \\ ${ }^{3}$ University B.I.S. group of institutions, Punjab Technical University, Punjab, India \\ ${ }^{4}$ Centre for Studies in Science of Life, Guglielmo Marconi University, Rome, Italy
}

"Corresponding author: Massimo Fioranelli, Centre for Studies in Science of Life, Guglielmo Marconi University, Rome, Italy, Tel: +3906802206007; E-mail: massimo.fioranelli@gmail.com

Rec date: Nov 14, 2014; Acc date: Nov 14, 2014; Pub date: Nov 16, 2014

Copyright: (C) 2014 Setacci F et al. This is an open-access article distributed under the terms of the Creative Commons Attribution License, which permits unrestricted use, distribution, and reproduction in any medium, provided the original author and source are credited.

Keywords: Aortic infection; Endografts; Mycotic aneurysm

\section{Introduction}

Aortic infection is an uncommon but severe condition, regardless of whether it occurs in the setting of bacteremia (mycotic aneurysm) or as a complication of atherosclerotic aneurysm or pseudoaneurysm after open aortic surgery. Frequently, aortic infection is associated with a primary or secondary fistula into the esophagus or upper airway in the thorax or the gastrointestinal system in the abdomen. In these cases the onset of symptoms could be directly an acute bleeding requiring emergency treatment. Sometimes the patients could develop sepsis. Conventional open surgical repair (OR) is still today considered the best treatment but is associated with considerable morbidity and mortality. In this setting, endovascular aneurysm repair (EVAR) appears to offer promise when used for emergency and palliative treatment especially in high-risk patients. EVAR is even more appealing when OR is complicated by the presence of inflammation, scarring, bleeding, or hemodynamic instability. In the last decade, a number of case reports of successful initial treatment of aortic infections using EVAR have been reported, suggesting wider use of this approach. But when are endografts the best treatment for aortic infection? And when are they not?

\section{Endograft for Mycotic Aneurysm}

Nowadays, mycotic aortic aneurysms represent $1 \%$ to $2 \%$ of all aortic aneurysms [1]. The "gold standard" of therapy involves surgical resection of the infected aorta, debridement of infected peri-aortic tissues, and reconstruction of aortic flow by either an in situ interposition of silver graft/homograft or extra-anatomic bypass followed by long-term antibiotic therapy [2]. Unfortunately, OR in patients in poor clinical condition, and with severe associated comorbidities, still results in high morbidity and mortality (up to $40 \%$ ) [3]. During the last years EVAR has been proposed as alternative in the management of such aneurysms. The procedure offers technical advantages compared with OR, but concerns remain about endograft placement in an infected field. The first reported case of EVAR for mycotic aneurysms was by Semba et al. [4]. After this report, several authors have described similar endovascular approaches with remarkable results [5-12]. Nevertheless, whether EVAR or TEVAR can actually be considered as definitive treatment for mycotic aneurysms remains an open question.

\section{Endograft for Aorto-bronchial Fistula}

Aortobronchial Fistulas (ABFs) are defined as communications between the thoracic aorta and the adjacent tracheobronchial system [13], generating aortic infection and acute bleeding. ABFs can developed in different thoracic aorta pathologies, including atherosclerotic aneurysms, penetrating aortic ulcers, anastomotic pseudoaneurysms after open aortic surgery, mycotic aneurysms, and traumatic thoracic aorta injuries [14]. ABFs are highly fatal if not diagnosed and treated quickly. Although clinical presentation is typical: hemoptysis, either intermittent or massive, a definitive diagnosis is not easy because there is no diagnostic test that can clearly demonstrate the presence of the fistula. In fact, computed tomography imaging rarely shows the communication between the aorta and the esophagus. Suggestive indirect signs of the fistulous tract are present in many cases and include air bubbles into the aorta, periaortic fluid collection, esophageal wall thickening, and lung parenchymal changes. Despite advances OR techniques, open repair still has a high operative mortality ranging from $15 \%$ to $41 \%$ related to the thoracotomy [15], the need for cross-clamping of the descending thoracic aorta, and direct repair or arterial bypass of the aortic defect, with concomitant resection or reconstruction of involved bronchial segments. The first TEVAR for ABF was described by Chuter et al. [16]. With refinement of endovascular techniques, TEVAR now represents a valid alternative for ABFs, offering the advantage of fast control of bleeding and avoiding major trauma related with OR. Experience is still limited because of the rarity of this clinical condition. The available data are largely restricted to individual case reports or small series [17-19].

Several concerns still remain about the potential of ABFs recurrence, persistent endograft infection, and late endograft complications, such as migration, remodeling, or disconnection. Whether TEVAR is a definitive procedure for ABF or a temporizing treatment to obtain prompt bleeding control remains to be defined. Unfortunately, little is still known about the long-term durability of TEVAR for this condition.

\section{Endograft for Aorto-enteric Fistulas}

Aortoenteric fistula (AEF) is defined as abnormal communication between the aortic and the bowel lumen with high risk of aortic infection and acute bleeding. AEF is a serious condition requiring immediate surgical intervention. We can classify AEFs in primary and secondary. The first can take place either as a primary procedure involving the aorta and the gastrointestinal tract or, more frequently, secondary to previous aortic reconstructive surgery or endovascular 
repair. Primary AEFs are extremely rare, ranging from $0.02 \%$ to $0.07 \%$ in autopsy studies. However, during the past 3 decades, erosion of the bowel (usually the distal duodenum) by prosthetic vascular grafts has become a more common cause and secondary AEFs have been reported to have reached an incidence of up to $4 \%$ in patients after aortic reconstruction, usually for aortic aneurysm. Symptoms at onset include hemodynamic instability secondary to gastrointestinal haemorrhage with or without signs of sepsis. The objective included bleeding control, maintenance of adequate distal perfusion, and control of infection. OR might achieve all three goals, but is accompanied by high morbidity and mortality rates (biblio) $[20,21]$.

The OR strategy for revascularization included the aortic replacement with the interposition of silver graft or homograft. The extra anatomical revascularization associated with infrarenal aortic stump suture is associated with high risk of post-operative aortic bleeding due to erosion of the aortic stump suture line and long-term patency of the extra-anatomical revascularization.

EVAR can be considering a valid therapeutic option especially in case of haemodynamic instability. In fact this strategy represents a bridge option allowing definitive repair at a later time, after optimization of the patients' condition [22].

\section{When are Endografts the Best Treatment for Aortic Infection? and when are they not?}

According with the most recent reported series and with our experience the endovascular repair can be considered a valid alternative option compared with classical open surgery in case of aortic infection but in selected patients. In several cases it could be considered also as the best and definitive treatment. For example in high risk and old patients considered unfit for open repair even after the stabilization of clinical condition. In this kind of patients the only endovascular therapy associated with adequate antibiotic therapy could be enough and can decrease radically the mortality associated with the treatment of this cohort of patients.

EVAR represents also the best treatment in case of haemodynamic instability of the patients and offers the possibility to stabilize their clinical condition in order to get to the definitive treatment in better conditions.

In younger patients without significant comorbidities the best therapeutic option remain still today the classical open surgery who allows the definitive solution of the problem and the endovascular repair should be indicated as "bridge approach" only in case of haemodynamic instability. Finally a feasible emergency-treatment option for aorto-bronchial and aorto-esophageal is to stop the aortic bleeding with TEVAR, then to remedy the esophageal or bronchial defect the interposition of intercostal muscle flap could be useful.

\section{References}

1. Moneta GL, Taylor LM Jr, Yeager RA, Edwards JM, Nicoloff AD, et al. (1998) Surgical treatment of infected aortic aneurysm.Am J Surg 175: 396-399.

2. Luo CY, Ko WC, Kan CD, Lin PY, Yang YJ (2003) In situ reconstruction of septic aortic pseudoaneurysm due to Salmonella or Streptococcus microbial aortitis: long-term follow-up. J Vasc Surg 38: 975-982.
3. Kyriakides C, Kan Y, Kerle M, Cheshire NJ, Mansfield AO, et al. (2004) 11-year experience with anatomical and extra-anatomical repair of mycotic aortic aneurysms. Eur J Vasc Endovasc Surg 27: 585-589.

4. Semba CP, Sakai T, Slonim SM, Razavi MK, Kee ST, et al. (1998) Mycotic aneurysms of the thoracic aorta: repair with use of endovascular stentgrafts. J Vasc Interv Radiol 9: 33-40.

5. Liu WC, Kwak BK, Kim KN, Kim SY, Woo JJ, et al. (2000) Tuberculous aneurysm of the abdominal aorta: endovascular repair using stent grafts in two cases. Korean J Radiol 1: 215-218.

6. Madhavan P, McDonnell CO, Dowd MO, Sultan SA, Doyle M, et al. (2000) Suprarenal mycotic aneurysm exclusion using a stent with a partial autologous covering. J Endovasc Ther 7: 404-409.

7. Kinney EV, Kaebnick HW, Mitchell RA, Jung MT (2000) Repair of mycoticparavisceral aneurysm with a fenestrated stent-graft. J Endovasc Ther 7: 192-197.

8. Ishida M, Kato N, Hirano T, Shimono T, Yasuda F, et al. (2002) Limitations of endovascular treatment with stent-grafts for active mycotic thoracic aortic aneurysm. Cardiovasc Intervent Radiol 25: 216-218.

9. Van Doorn RC, Reekers J, de Mol BA, Obertop H, Balm R (2002) Aortoesophageal fistula secondary to mycotic thoracic aortic aneurysm: endovascular repair and transhiatalesophagectomy. J Endovasc Ther 9: 212-217.

10. Rayan SS, Vega JD, Shanewise JS, Kong LS, Chaikof EL, et al. (2004) Repair of mycotic aortic pseudoaneurysm with a stent graft using transesophageal echocardiography. J Vasc Surg 40: 567-570.

11. Jones KG, Bell RE, Sabharwal T, Aukett M, Reidy JF, et al. (2005) Treatment of mycotic aortic aneurysms with endoluminal grafts.Eur J Vasc Endovasc Surg 29: 139-144.

12. Lee KH, Won JY, Lee do Y, Choi D, Shim WH, et al. (2006) Stent-graft treatment of infected aortic and arterial aneurysms. J Endovasc Ther 13: 338-345.

13. MacIntosh EL, Parrott JC, Unruh HW (1991) Fistulas between the aorta and tracheobronchial tree. Ann Thorac Surg 51: 515-519.

14. Riesenman PJ, Brooks JD, Farber MA (2009) Thoracic endovascular aortic repair of aortobronchial fistulas. J Vasc Surg 50: 992-998.

15. Picichè M, De Paulis R, Fabbri A, Chiariello L (2003) Postoperative aortic fistulas into the airways: etiology, pathogenesis, presentation, diagnosis, and management. Ann Thorac Surg 75: 1998-2006.

16. Chuter TA, Ivancev K, Lindblad B, Brunkwall J, Arén C, et al. (1996) Endovascular stent-graft exclusion of an aortobronchial fistula. J VascInterv Radiol 7: 357-359.

17. Saratzis A, Saratzis N, Fillipou D (2005) Endovascular stent-graft repair of an aortobronchial fistula: case report and review of the literature. Eur J Vasc Endovasc Surg Extra 9:123-125.

18. Wheatley GH 3rd, Nunez A, Preventza O, Ramaiah VG, RodriguezLopez JA, et al. (2007) Have we gone too far? Endovascular stent-graft repair of aortobronchial fistulas. J Thorac Cardiovasc Surg 133: 1277-1285.

19. Kokotsakis J, Misthos P, Athanasiou T, Romana C, Skouteli E, et al. (2007) Endovascular stenting for primary aortobronchial fistula in association with massive hemoptysis. Tex Heart Inst J 34: 369-372.

20. Antoniou GA, Koutsias S, Antoniou SA, Georgiakakis A, Lazarides MK, et al. (2009) Outcome after endovascular stent graft repair of aortoenteric fistula: A systematic review. J Vasc Surg 49: 782-789.

21. Kakkos SK, Antoniadis PN, Klonaris CN, Papazoglou KO, Giannoukas $\mathrm{AD}$, et al. (2011) Open or endovascular repair of aortoenteric fistulas? A multicentre comparative study. Eur J Vasc Endovasc Surg 41: 625-634.

22. Chisci E, de Donato G, Setacci F, Stella A, Setacci C (2007) Recurrent aortoenteric fistula: two different bridge solutions. Vascular 15: 235-237. 